\title{
МЕТРОЛОГІЧНІ АСПЕКТИ ВИМІРЮВАНЬ ПРОСТОРОВИХ ПАРАМЕТРІВ ХОДИ
}

\author{
Антонова-Рафі Ю. В., доцент \\ Antonova-rafi@ukr.net \\ Худецький І.Ю., професор \\ igorkhudetskyy@gmail.com \\ Інтелегатор Д.О., аспірант \\ danil.intel@gmail.com \\ Факультет біомедичної інженерії \\ Національний технічний університет України \\ «Київський політехнічний інститут імені Ігоря Сікорського» \\ м. Київ, Україна
}

\begin{abstract}
Реферат - На основі методів вимірювань запропоноване технічне завдання на розробку методики вимірювань просторових параметрів ходи, яка використовується при біомеханічних дослідженнях руху людини в нормі і при патологіі опорно-рухової та інших систем організму людини. Визначена похибка вимірювань, щуо складається з трьох окремих похибок: інструментальної, методичної та нестабільності вимірювальних параметрів шагу.

В статті запропоновано технологію вимірювань, їх підрахунок та побудовано схему вимірів. Завдяки подібній системі можна побудувати засоби визначення вимірювань просторових параметрів кроку. $B$ подальшому ию методику можна реалізація в програмному середовищі, щчо забезпечить універсальність та простоту подальшої модифікації алгоритмів роботи. Тематика статті стосується наукових досліджень у сфері охорони здоров'я та медичних технологій.
\end{abstract}

Ключові слова - біомеханічні дослідження ходи, іхнографія, методика виконання вимірювань, фізична терапія, просторові параметри ходи, похибки вимірювань.

\section{І. ВСТУП}

Науково - технічний та економічний розвиток суспільства неможливий без поступового підвищення якості вимірювань на основі неперервного метрологічного вдосконалення стандартизації та сертифікації. Правові та економічні основи системи метрологічної стандартизації та сертифікації встановлені декретами кабінету міністрів України «Про забезпечення єдності вимірювання» 26 квітня 1993 року, «Про стандартизацію та сертифікацію» 10 травня 1993, а також законами України «Про метрологію i метрологічну діяльність» 11 млютого 1998p., «Про стандартизацію» 17 травня $2001 \mathrm{p}[1,2]$.

Стандартизація, метрологія i вимірювальна техніка $є$ основними ланками, рівень і темпи розвитку найбільш впливають на якість не лише усієї промислової продукції, а і на якість фізичної терапії, ерготерапії та реабілітації [3].

Іхнографія - це свого роду вимірювання та дослідження ходи, а також форми ступні за іiі відбитками є відомим та доступним методом виконання вимірювань просторових параметрів кроку [3]. Діагностична інформативність методу, доведена при різних видах патології опорнорухової системи, значно підвищується при вимірюванні функціональних проб, зокрема, в різних режимах і умовах пересування людини. Останні часто використовуються в стандартних та індивідуальних програмах біомеханічних досліджень і реабілітації $[7,4]$.

Разом 3 цим, i досі не дуже розповсюджена єдина методика виконання вимірювань (MBB) просторових параметрів ходи, створення якої є особливо актуальною в світлі забезпечення єдності вимірювань згідно Закону України «Про метрологію та метрологічну діяльність» від 5 червня 2014 року № 1314-VII $[1,2]$.

\section{II. МЕТА ДОСЛІДЖЕННЯ}

Мета роботи: на основі методу іхнографіi розробити технічне завдання 3 методики виконання вимірювань просторових 
параметрів ходи і визначити iii основні метрологічні характеристики.

\section{III. МАТЕРІАЛИ І МЕТОДИ}

Запропонована методика виконання вимірювань призначена для вимірювання просторових параметрів кроку при ході і може бути використана в науково-дослідних і лікувальних установах ортопедотравматологічного та неврологічного профілю, центрах відновної медицини і реабілітації, в медико-соціальній експертизі та доказовій медицині.

3 характеристик MBB: діапазон вимірювань лінійних параметрів кроку - від 0 до 200 см, кутів розвороту стоп від $-90^{0}$ до $+90^{0}$, відносних параметрів - від 0 до 100\%. Абсолютна похибка вимірювання довжини подвійного кроку становить $\pm 1,5$ см.

Основні терміни, які використовуються в MBB:

- середня лінія - пряма лінія, розмічена уздовж по середині іхнографічної доріжки;

- слід - відбиток стопи на іхнографічній доріжці;

- пара слідів - найближчі один до одного правий і лівий сліди;

- вісь сліду - лінія, проведена уздовж сліду через середину відбитка другого пальця стопи і задню точку сліду;

- задня точка сліду - середина п'яткового краю сліду, визначена візуально;

- параметри кроку - кількісні характеристики елементів кроку;

- лінійні параметри кроку - довжина і база кроку;

- просторові параметри кроку - лінійні параметри кроку і кути розвороту стоп;

- довжина кроку - відстань уздовж середньої лінії між однойменними точками лівого i правого слідів. При розташуванні правого сліду попереду лівого - це правий крок, лівого сліду попереду правого - лівий крок;

- довжина подвійного кроку - відстань уздовж середньої лінії між однойменними точками двох найближчих слідів однієї і тієї ж стопи; сума довжин лівого і правого кроків;

- база кроку - відстань від задньої точки сліду по нормалі до середньої лінії; від лівого сліду - база лівого кроку, від правої сліду - база правого кроку;
- база подвійного кроку - сума баз лівого i правого кроків;

- кут розвороту стопи - кут між віссю сліду і середньою лінією: для лівого сліду - кут розвороту лівої стопи, для правого сліду - кут розвороту правої стопи;

- повний кут розвороту стоп - сума кутів розвороту правої і лівої стоп;

- відносні параметри кроку - відношення лінійних параметрів кроку до однойменних параметрів подвійного кроку; відношення кута розвороту лівої (правої) стопи до повного кута розвороту стоп;

- нестабільність (варіативність) параметрів кроку - випадкові коливання параметрів кроку, обумовлені індивідуальною особливістю ходи пацієнта.

При виконанні вимірювань застосовують такі засоби: лінійка сталева 1000 мм; стенд для ходьби у вигляді замкненого периметра 3 горизонтальними та похилими ділянками, кожна з яких довжиною не менше 10 м; іхнографічна доріжка 3 темного лінолеуму довжиною не менше 10 м, якою покривають стенд; тальк або крейда для обробки стоп пацієнта; тонка крейда для обведення; таблиці тригонометричних функцій. Допускається замінювати зазначені речі іншими, які не поступаються їм за технічними, метрологічними та експлуатаційними характеристиками.

Суть методики виконання вимірювань можна описати наступним чином: Для отримання іхнограми пацієнт проходить по іхнографічній доріжці без взуття, при цьому поверхня подошви його стоп оброблена тальком або крейдою. На темній поверхні доріжки залишаються контрастні білі сліди, за якими вимірюють просторові параметри ходи. Приклад іхнограми представлений на малюнку 1.

На кожному з слідів іхнограми, крім першого і останнього, проводять розмітку: визначають задню точку сліду (ЗТС) i проводять через неї перпендикуляр до середньої лінії (СЛ) і вісь сліду (ВС) до перетину 3 середньою лінією. На кожному розміченому сліді за допомогою лінійки вимірюють довжину кроку L, базу кроку D i довжину осі сліду Е від задньої точки ЗТС до середньої лінії СЛ. За результатами вимірювання бази D і довжини осі сліду Е за 
допомогою тригонометричних визначають кут розвороту стопи:

$$
\alpha=\arcsin \frac{D}{E} \text {. }
$$

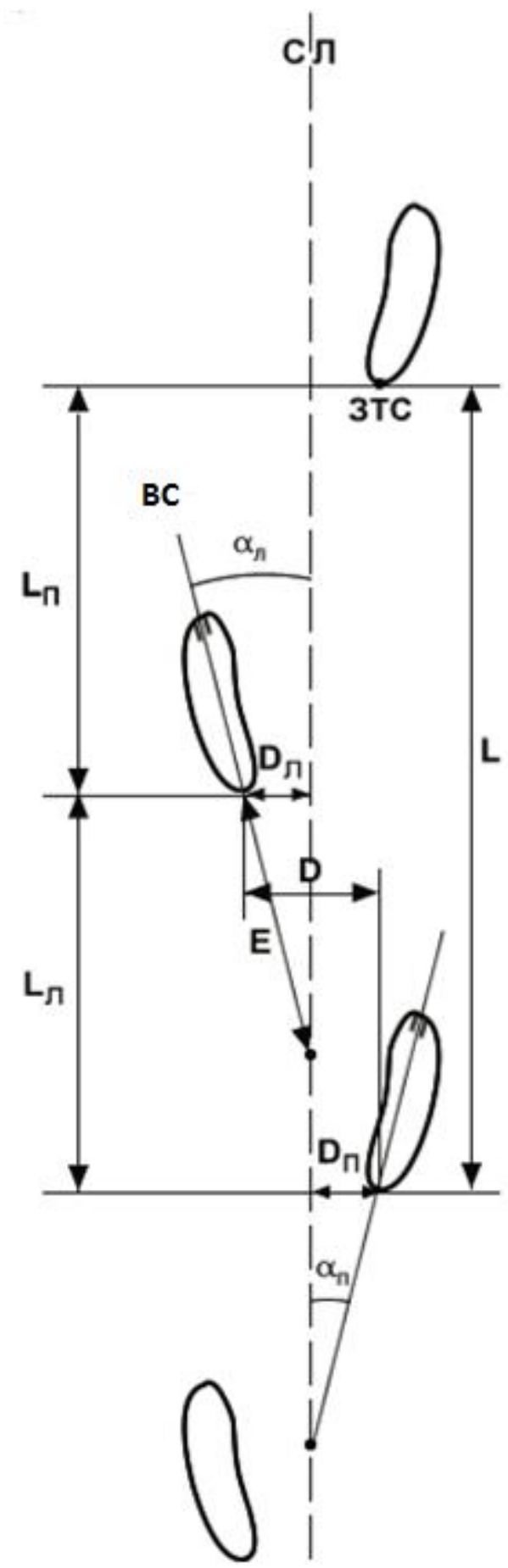

Рис. 1. Схематичне зображення іхнограми.

СЛ - середня лінія, ЗТС - задня точка сліду, ВС - вісь стопи, Е - довжина осі стопи від ЗТС до перетину з СЛ, Lп - довжина правого кроку, Lл - довжина лівого кроку, L - довжина подвійного кроку, Dл - база лівого кроку, Dп база правого кроку, D - база подвійного кроку, $\alpha$ л - кут розвороту лівої стопи, $\alpha_{\text {п }}$ - кут розвороту правої стопи.

Практично параметри послідовних шагів відрізняються один від одного випадковим чином, тобто мають місце випадкові коливання параметрів ходи. Щоб згладити ці коливання, визначають середні значення параметрів, для чого обміряють 3-5 шагів. При необхідності можуть бути додатково визначені максимальні та середні (середньоквадратичні) відхилення параметрів окремих кроків від середніх значень. Для надійної оцінки цих характеристик необхідно провести реєстрацію і обробку достатньо великої кількості кроків (не менше 10). Заміри на горизонтальній поверхні і на поверхні 3 нахилом (на різних ділянках) доріжки проводяться окремо.

Похибка вимірювань просторових параметрів кроку за цією методикою МBB складається з трьох складових:

- $\quad$ інструментальної похибки засобів вимірювань (лінійки);

- методичної похибки, пов'язаної зі способом розмітки і обміру іхнограми;

- нестабільністю (варіативністю) параметрів кроку, що вимірюються.

Інструментальна похибка пов'язана 3 ціною поділу лінійки і дискретністю відліку, які в даному випадку дорівнюють 1 мм. Граничне значення такої похибки $\Delta_{\text {п }}$ становить $\pm 0,5 \mathrm{Mm}$ при рівномірному розподілі ймовірності, а середньоквадратичне значення $\sigma_{1} \approx 0,3$ мм. Така абсолютна похибка супроводжує вимір будь-яких лінійних параметрів L, D, E, незалежно від їх розміру.

Методична похибка обумовлена кінцевою шириною ліній розмітки СЛ, ВС і D, а також наявною нечіткістю їх кордонів і меж слідів. Щоб виключити вплив ширини середньої лінії (СЛ), слід проводити всі вимірювання від однієї іiі межі, наприклад лівої. За наявного досвіду невизначеність кордонів слідів може досягати 3-5 мм, ширина крейдяної вісі сліду (ВС) - близько 2-3 мм.

Ці причини можуть призвести до абсолютної похибки одиничного вимірювання параметрів L, D і Е до $\pm 2,5$ мм (граничне значення) при одновимірному розподілі ймовірності, із середньоквадратичним значенням $\sigma_{1} \approx 1,5$ мм. Похибка вимірювання, що пов'язана 3 нестабільністю параметрів 
ходи, $\epsilon$ індивідуальною характеристикою пацієнта i може бути оцінена в кожному окремому випадку тільки за результатами іхнографічного дослідження.

3 практичного досвіду, нестабільність (розкид) довжини подвійного кроку може досягати 5,0cм, бази кроку $3,0 \mathrm{~cm}$, кута розвороту стоп $3^{\circ}$. При цьому відповідні похибки середніх результатів вимірювання п'яти кроків складуть $\pm 1,5 \mathrm{~cm}, \pm 1 \mathrm{~cm}, \pm 1^{\circ}$.

Порівнюючи чисельні оцінки окремих похибок, бачимо, що загальна похибка вимірювання параметрів кроку визначається в основному їх варіативністю (нестабільністю) і похибкою розмітки іхнограми; похибка лінійки істотно менше чим вони і не грає істотної ролі.

При виконанні конкретних вимірів розкид окремих результатів буде визначатися одночасним дією всіх джерел похибки. При статистичній обробці результатів вимірювань буде визначена оцінка сумарної, випадкової похибки за відомими формулами:

Середнє значення параметра:

$$
\overline{\mathrm{X}}=\frac{\sum \mathrm{X} i}{\mathrm{n}}(1) ;
$$

Розкид параметра:

$$
X=X_{\max }-X_{\min }(2)
$$

СКО одиничних вимірювань:

$$
\sigma_{\mathrm{i}}=\sqrt{\frac{\sum(\mathrm{Xi}-\overline{\mathrm{X}})^{2}}{(\mathrm{n}-1)}}(3) ;
$$

СКО середнього результату:

$$
\sigma_{\overline{\mathrm{x}}}=\frac{\sigma_{1}}{\sqrt{\mathrm{n}}}=\sqrt{\frac{\sum(\mathrm{Xi}-\overline{\mathrm{X}})^{2}}{\mathrm{n}(\mathrm{n}-1)}}(4) ;
$$

де $\mathrm{X}$ - будь-який параметр лівого (правого) кроку: L, D, $\alpha$;

$\overline{\mathrm{X}}$ - середнє значення параметра;

i - номер параметра за схемою кроку;

n - кількість обміряних кроків;

$\sigma$ i - СКО одиничного вимірювання X i ;

$\sigma_{\overline{\mathrm{x}}}$ - СКО середнього значення.

Оскільки найбільшою з трьох окремих похибок $\epsilon$ нестабільність параметрів кроку, саме вона визначатиме i розподілення ймовірності сумарної похибки. Можна стверджувати, що воно буде близьким до нормального.

При невеликій кількості вимірів (3-5) кожного параметра кроку найбільш простою і достатньо надійною оцінкою граничного значення похибки одиничних вимірювань $\epsilon$ половина розкиду $\Delta \mathrm{X}$ :

$$
\Delta_{1}= \pm \frac{\Delta X}{2}= \pm \frac{\left(X_{\max }-X_{\min }\right)}{2}(5) ;
$$

Похибка середнього результату з n вимірювань складе:

$$
\Delta_{\overline{\mathrm{X}}}= \pm \frac{\Delta_{1}}{\sqrt{n}}= \pm \frac{\mathrm{X}_{\max }-\mathrm{X}_{\min }}{2 \sqrt{\mathrm{n}}}(6) ;
$$

Виконання вимірювань i обробка результатів проводяться наступним чином. На слідах, які підлягають вимірюванню, виконують розмітку іхнограми:

- крейдою відзначають задні точки слідів;

- по лінійці крейдою проводять осі слідів і бази слідів до перетину з середньою лінією (на перших і останніх слідах розмітку не виконують).

На іхнограмі вимірюють 3-5 кроків. За допомогою лінійки вимірюють довжину $\mathrm{L}_{л}($ п), базу $\mathrm{D}_{л}\left(\right.$ п) i довжину осі сліду $\mathrm{E}_{л}($ п) кожного кроку відповідно до малюнка.

Далі здійснюють розрахунок параметрів кроку:

- обчислюють довжину i базу подвійного кроку по кожній парі слідів;

- обчислюють відношення:

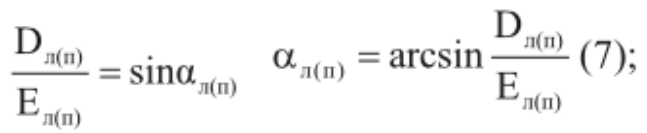

і по тригонометричним таблицям визначають кут розвороту стопи:

- обчислюють повний кут розвороту стоп по кожній парі слідів $\alpha=\alpha_{л}+\alpha_{\text {п }}$;

- обчислюють середні значення параметрів за формулою (1);

- обчислюють розкид параметрів за формулою (2).

Характеристики похибки вимірювань вираховують за формулами 3, 4 і 6 .

Розрахунок відносних параметрів довжини $\mathrm{L}_{\text {л (п) }}$ i кута розвороту стопи $\alpha$ л (п) проводять за формулою:

$$
\mathrm{X}_{\pi(\mathrm{II})}=\frac{\overline{\mathrm{X}}_{\text {Л(II) }}}{\overline{\mathrm{X}}}(8),
$$

де $\mathrm{X}$ л (п) - відносний параметр одиничного лівого (правого) кроку; 


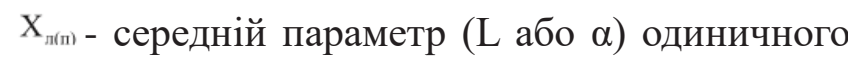
лівого (правого) кроку;

$\overline{\mathrm{X}}$ - середній параметр подвійного кроку.

\section{IV. РЕЗУЛЬТАТИ ТА ОБГОВОРЕННЯ}

Більшість модулів системи в автоматичному режимі налаштовуються на оптимальний режим, наприклад, як раніше згадувалось, в модулі IMAQ AutoBThreshold 2 поріг бінаризації визначається автоматично.

\section{V. ВИСНОВКИ}

Таким чином, на основі методів вимірювань запропоноване технічне завдання на розробку методики вимірювань просторових параметрів ходи, яка використовується при біомеханічних дослідженнях руху людини в нормі і при патології опорно-рухової та інших систем організму людини; розроблена методика виконання вимірювань, визначені ㄲi1 метрологічні характеристики $[7,8]$ та досліджена доцільність іiі використання при реабілітації та фізичній терапії.

При проведенні достатньої кількості спостережень і подальшій статистичній обробці отриманих результатів ми зможемо цю методику практично застосувати в сфері охорони здоров'я, реабілітації, фізичній терапії, ерготерапії.

\section{ПЕРЕЛІК ПОСИЛАНЬ}

[1] http://zakon.rada.gov.ua/laws/show/40-93?lang=ru

[2] ДСТУ 2709-94. Державна система забезпечення єдност вимірювань. Автоматизовані системи керування технологічними процесами. Метрологічне забезпечення. Основні положення.

[3] Андрєєва Р. І. Біомеханіка і основи метрології: [навчально-методичний посібник / для здобувачів ступеню вищої освіти “бакалавр” денної та заочної форм навчання спеціальностей 6.010201. Фізичне виховання*, 6.010202. Спорт, 6.010203. Здоров'я людини*] // Регіна Андрєєва. - Херсон: ПП Вишемирський В. С., 2015. - 224 c.

[4] Белянин О.Л. Стандартизация и индивидуализация функционально-биомеханического обследования ортопедического больного / О.Л. Белянин, Л.М. Смирнова // Научно-практическая конференция по вопросам обеспечения инвалидов техническими средствами реабилитации, Санкт- Петербург, 26-28 ноября 2008. СПб., 2008. - С. 6-7.

[5] Р. Ф. Ахметов Біомеханіка фізичних вправ: Навчальний посібник. - Житомир: Житомирський державний педагогічний університет імені Івана Франка, 2004. - 124 c.

[6] Дубровский В.И. Биомеханика / В.Н. Дубровский, В.Н. Федорова. - М.: Изд-во ВЛАДОС- ПРЕСС, 2003. - 672 с.

[7] Вимірювальна техніка та метрологія : міжвідомчий науково-технічний збірник / Міністерство освіти і науки України, Національний університет «Львівська політехніка» ; відповідальний редактор Б. І. Стадник. Львів : Видавництво Львівської політехніки, 2019. Випуск 80 (1). -80 с. : іл.

[8] Мягченко О.П. Біомеханіка людини Підручник для студентів факультетів фізичного виховання вищих навчальних закладів третього та четвертого рівнів акредитації - Бердянськ: Азовпринт 2015 р. - 215 с. 


\title{
МЕТРОЛОГИЧЕСКИЕ АСПЕКТЫ ИЗМЕРЕНИЙ ПРОСТРАНСТВЕННЫХ ПАРАМЕТРОВ ПОХОДКИ
}

Антонова-Рафи Ю. В., доцент

Antonova-rafi@ukr.net Худецкий И.Ю., профессор igorkhudetskyy@gmail.com

Интелегатор Д.О., аспирант danil.intel@gmail.com

Факультет биомедицинской инженерии Национальный технический университет Украины «Киевский политехнический институт имени Игоря Сикорского»

г. Киев, Украина

Реферат - На основе методов измерений предложено техническое задание на разработку методики измерений пространственных параметров походки, которая используется при биомеханических исследованиях движения человека в норме и при патологии опорно-двигательной и других систем организма человека. Определена погрешность измерений, состоящая из трех отдельных погрешностей: инструментальной, методической и нестабильности измерительных параметров шага.

В статье предложена технология измерений, их подсчет и построена схема измерений. Благодаря подобной системе можно построить средства определения измерений пространственных параметров шага. В дальнейшем эту методику можно реализация в программной среде, что обеспечит универсальность и простоту дальнейшей модификации алгоритмов работьы. Тематика статьи касается научных исследований в сфере здравоохранения и медицинских технологий.

Ключевые слова - биомеханические исследования походки, ихнография, методика выполнения измерений, пространственные параметры шага, погрешности измерений.

\section{UDC 531.751}

\section{METROLOGICAL ASPECTS OF MEASUREMENTS OF SPATIAL PARAMETERS}

\author{
Antonova-Rafi Yu., assistant professor \\ antonova-rafi@ukr.net \\ Khudetskyy I., professor \\ igorkhudetskyy@gmail.com \\ Inteleghator D., PHD student \\ danil.intel@gmail.com \\ Faculty of Biomedical Engineering \\ National Technical University of Ukraine \\ "Igor Sikorsky Kyiv Polytechnic Institute"
}

Kyiv, Ukraine

Abstract - On the basis of measurement methods, a technical specification for the development of a technique for measuring the spatial parameters of gait is proposed, which is used in biomechanical studies of human movement in normal and pathology of the musculoskeletal and other systems of the human body. Measurement error, consisting of three individual errors: instrumental, methodological and instability of step measurement parameters, is determined.

In the article the technology of measurements, their calculation and the scheme of measurements are offered. With this system, you can build tools for determining the measurements of the spatial parameters of the step. In the future, this technique can be implemented in a software environment, which will provide versatility and ease of further modification of the algorithms. The subject of the article is related to scientific research in the field of health care and medical technologies.

Keywords - biomechanical studies of gait, ekhonography, measurement technique, spatial step parameters, measurement errors. 